\title{
Optimal Allocation of Pollutant from Non-point Sources in Watershed
}

\author{
Alok Kumar ${ }^{1}$, Shigeya Maeda ${ }^{1}$ and Toshihiko Kawachi ${ }^{2}$
}

\begin{abstract}
A linear programming model is developed to optimize the allocation of pollutant from nonpoint sources in a watershed. The use of ArcView GIS software is incorporated to calculate the flow length from each land management unit as a non-point source to the outlet of the watershed. The formulated model is applied to a subcatchment of Yasu river basin in Shiga prefecture, Japan. Optimization is carried out at different weight values depending on decision-maker's preference order of land management unit type with respect to mean load discharged from unit area. It is observed that optimum discharged load of total nitrogen changes with the change in preference order. This model can be useful for determining optimum discharged pollutant loads from different land management units of a watershed for different preference orders based on need of decision-makers.
\end{abstract}

Keywords: Non-point pollutant sources; Optimization; GIS; Total nitrogen; Watershed

\section{Introduction}

Water is one among the most essential natural resources needed by plants, animals and humans to sustain their life. In the past, people were concerned mainly about quantitative conservation of water, but recently emphasis is also being given to qualitative aspects of water resources (Rejesus and Hornbaker, 1999; Basnyat et al., 2000). Water resources are classed either as surface or sub-surface sources of water. Surface water (Rivers, Ponds, etc.) receive most of pollutants from point sources and/or nonpoint sources. Point sources are easily identifiable and have known discharged volume, thus being relatively easier to manage (Leon et al., 2000). On the contrary, non-point sources (e.g., agricultural and domestic) are considered to be difficult to manage due to their wide spatial distribution. Additionally, there is no regulation as yet with regard to the upper limit of pollutant from these sources.

Researches have been conducted in the direction of analyzing and estimating pollutant from non-point sources (Young et al., 1989; Ha et al., 1998; Leon et al., 2000) and its role in the development of water quality management plan for watershed (Pegram and Bath, 1995). But less attention has been paid to optimization of allocated discharged pollutant load from non-point sources. Randhir et al. (2000) developed a multi-objective dynamic spatial optimization algorithm using biophysical simulation models AGNPS (Agricultural Nonpoint Source) and EPIC (Erosion Productivity Impact Calculator) and Geographic Information Systems (GIS). However, they considered only agricultural watershed and they also did not take into account the decay factor, which plays important role as the pollutants travel along

\footnotetext{
${ }^{1}$ Postgraduate Student, Graduate School of Agricultural Science, Kyoto University, Kitashirakawa-oiwake-cho, Sakyoku, Kyoto, 606-8502 Japan

${ }^{2}$ Professor, Graduate School of Agricultural Science, Kyoto University, Kitashirakawa-oiwake-cho, Sakyo-ku, Kyoto, 6068502 Japan
}

their courses. Thus there is a need to look into related issues more deliberately.

In this study, a model is developed to optimize the allocation of pollutant load from non-point sources in a watershed by combining optimization theory and GIS technique. The use of GIS facilitates easy handling of data on parameters that have wide spatial variations. GIS is a computer system capable of spatially representing data on the land surface and linking additional data, related to this spatial depiction, through tables and charts. To demonstrate the developed model's ability, it is applied to a study area in Shiga prefecture, Japan, which determines an optimum allocation of discharged loads of total nitrogen from land management units (LMUs).

\section{Methodology}

\subsection{Modeling watershed using GIS}

Modeling of study area is done using the Spatial Analyst module of ArcView GIS (ESRI, 1996). For this purpose, DEM (Digital Elevation Model), in raster format, having grid size of $50 \mathrm{~m} \times 50 \mathrm{~m}$ and landuse map, in vector format, are used. DEM contains data on the elevation at center of each grid. First, watersheds are delineated from the DEM in a relatively larger river basin. A watershed is an area draining water to a common outlet as concentrated drainage. All the sinks in DEM of delineated watersheds are filled then, in order to avoid draining of runoff from grids into each other and thus entering the process into a loop. Sink is defined as a grid having elevation lower than all its surrounding grids or two grids flowing into each other and thus having internal drainage instead of draining into a neighboring grid. From filled DEM of delineated watersheds, the flow direction for each grid is determined using the concept of the steepest slope to one of its eight neighboring cells (Figure 1). The central grid takes one out of the eight numbers indicating the flow direc- 


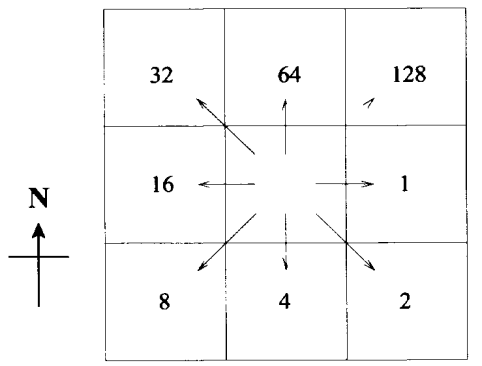

Figure 1: Flow direction values given by ArcView

tion. Based on the value of flow direction, the value of flow accumulation is calculated for each grid. Flow accumulation for a grid is defined as the number of upstream grids flowing into that grid. On the basis of flow accumulation values, the stream networks and thus the outlet of watersheds are determined. Grid cells with a high value of flow accumulation are areas of concentrated flow and are used to identify stream channels. Then out of these derived watersheds, one watershed, whose outlet attaches to a permanent river, is chosen as a study area in order to exclude the effect of the river flow on transport of pollutants. The flowlength from each grid, included in the study area (watershed), to the outlet is determined from the flow direction values. The study area is fragmented into LMU's which are polygons of landuse data. The area of each LMU is also derived using ArcView GIS.

\subsection{Optimization Model}

The pollutants released from non-point sources are first transferred to the streams and later transported along the stream or river. During their transfer from sources to the streams, the pollutant loads normally reduce in amount due to self-purification of watershed. This reduction can be assumed to be a function of the distance traveled. The reduction rate per unit length can be assumed to be proportional to the amount of discharged pollutant load from sources $(d L / d x=-\lambda L)$, and can be integrated to the form $L=L_{0} e^{-\lambda x}$. Based on these facts, the objective function and constraints for the optimization of pollutant load from non-point sources can be formulated as:

$$
\begin{array}{cc}
\operatorname{Maximize} & \sum_{i=1}^{I_{p}} A_{p_{i}} L_{p_{i}}+\sum_{i=1}^{I_{d}} A_{d_{i}} L_{d_{i}} \\
& +\sum_{i=1}^{I_{f}} A_{f_{i}} L_{f_{i}}+\sum_{i=1}^{I_{c}} A_{c_{i}} L_{c_{i}}
\end{array}
$$

subject to:

(i) Effluent limitation at the outlet of the watershed

$$
\begin{gathered}
\sum_{i=1}^{I_{p}} e^{-\lambda x_{p_{i}}} A_{p_{i}} L_{p_{i}}+\sum_{i=1}^{I_{d}} e^{-\lambda x_{d_{i}}} A_{d_{i}} L_{d_{i}}+ \\
\sum_{i=1}^{I_{f}} e^{-\lambda x_{f_{i}}} A_{f_{i}} L_{f_{i}}+\sum_{i=1}^{I_{c}} e^{-\lambda x_{c_{i}}} A_{c_{i}} L_{c_{i}} \leq \bar{L}
\end{gathered}
$$

(ii) Relations among mean effluents from different types of LMUs

$$
\begin{aligned}
& \frac{\sum_{i=1}^{I_{p}} A_{p_{i}} L_{p_{i}}}{\sum_{i=1}^{I_{p}} A_{p_{i}}}=\alpha \frac{\sum_{i=1}^{I_{d}} A_{d_{i}} L_{d_{i}}}{\sum_{i=1}^{I_{d}} A_{d_{i}}} \\
& \frac{\sum_{i=1}^{I_{p}} A_{p_{i}} L_{p_{i}}}{\sum_{i=1}^{I_{p}} A_{p_{i}}}=\beta \frac{\sum_{i=1}^{I_{f}} A_{f_{i}} L_{f_{i}}}{\sum_{i=1}^{I_{f}} A_{f_{i}}} \\
& \frac{\sum_{i=1}^{I_{p}} A_{p_{i}} L_{p_{i}}}{\sum_{i=1}^{I_{p}} A_{p_{i}}}=\gamma \frac{\sum_{i=1}^{I_{c}} A_{c_{i}} L_{c_{i}}}{\sum_{i=1}^{I_{c}} A_{c_{i}}}
\end{aligned}
$$

(iii) Lower limit of effluent in each LMU

$$
\begin{aligned}
L_{p_{i}} \geq L_{p_{i}}^{l} & & i=1,2, \ldots, I_{p} \\
L_{d_{i}} \geq L_{d_{i}}^{l} & & i=1,2, \ldots, I_{d} \\
L_{f_{i}} \geq L_{f_{i}}^{l} & & i=1,2, \ldots, I_{f} \\
L_{c_{i}} \geq L_{c_{i}}^{l} & & i=1,2, \ldots, I_{c}
\end{aligned}
$$

where $i=$ number of a LMU $(i=1,2, \ldots, I), p$, $f, c$, and $d=$ indices denoting paddy fields, forests, cities, and dry fields, respectively, $A_{i}=$ area of LMU $i\left(\mathrm{~m}^{2}\right), L_{i}=$ discharged pollutant load from LMU $i\left(\mathrm{~g} / \mathrm{m}^{2} / \mathrm{month}\right), x_{i}=$ average length of flow path for LMU $i$ to the outlet $(\mathrm{m}), \lambda=$ watershed-wide self-purification coefficient $\left(\mathrm{m}^{-1}\right), \bar{L}=$ effluent standard value of pollutant at the outlet of the watershed (g/month), $L_{i}^{l}=$ lower limit of pollutant load in LMU $i\left(\mathrm{~g} / \mathrm{m}^{2} / \mathrm{month}\right), \alpha, \beta$, and $\gamma=$ weights. The values of $\alpha, \beta$, and $\gamma$ depend on a decision-maker's preference order of LMU type in the sense of mean load discharged from an unit area.

The above-mentioned linear programming problem is solved to determine the optimum amount of pollutant $\left(L_{i}\right)$ that can be allocated to each LMU.

\section{Application}

\subsection{Study area}

A subwatershed of Yasu river basin is selected as the study area $\left(6.3 \mathrm{~km}^{2}\right)$, which finally drains into Biwa Lake (Figures 2 and 3 ). The runoff from the subcatchment flows directly into the Yasu river. Black line, in Figure 2, represents the channel predicted by ArcView and green color represents the natural water body, including river. It is observed that predicted channel networks match the natural channel. The flow length calculated for study area, using GIS, is shown in Figure 3. Darker bands in figure represent higher values of flow length and lighter bands represent lower values of flow length. The landuse pattern in the study area is shown in Figure 4. The area is dominated by forests and paddy fields mainly. In this area, there are altogether 30 LMU's including 7 units of paddy fields $\left(p_{1} \sim p_{7}\right), 5$ units of forest $\left(f_{1} \sim f_{5}\right), 9$ units of cities $\left(c_{1} \sim c_{9}\right)$, and 9 units of dry fields $\left(d_{1} \sim d_{9}\right)$ (Figure 4$)$. Therefore, 30 decision variables (one for each LMU) are considered in the objective function and constraints (1)-(9). 

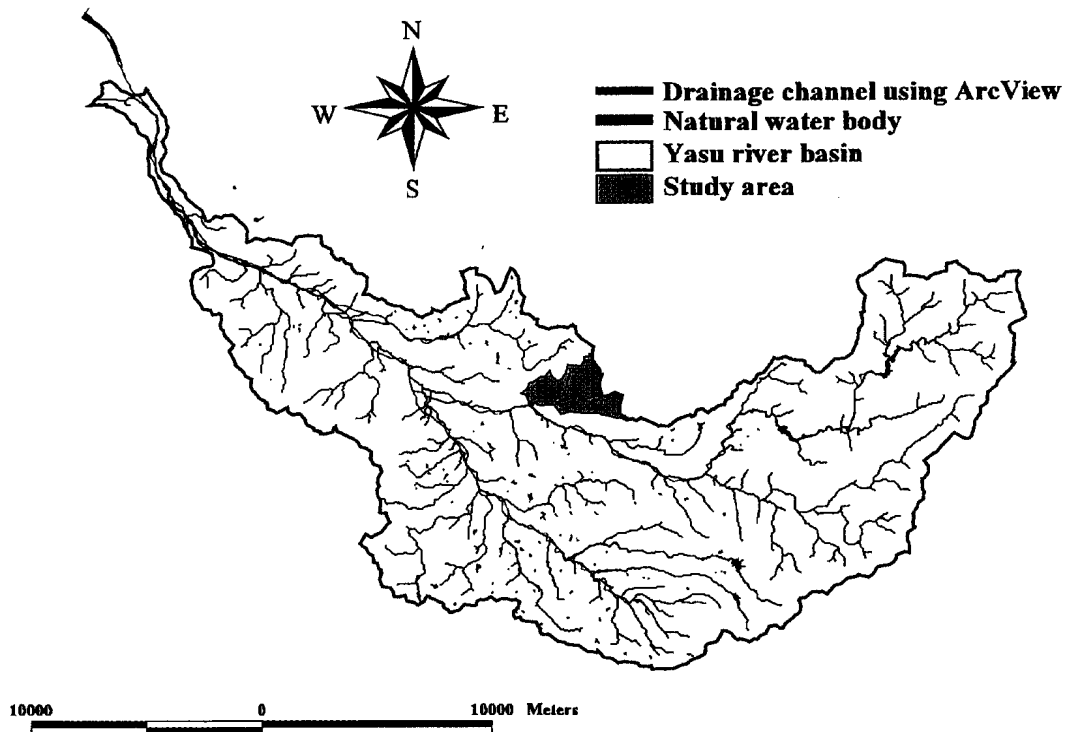

Figure 2: Map showing the Yasu river basin

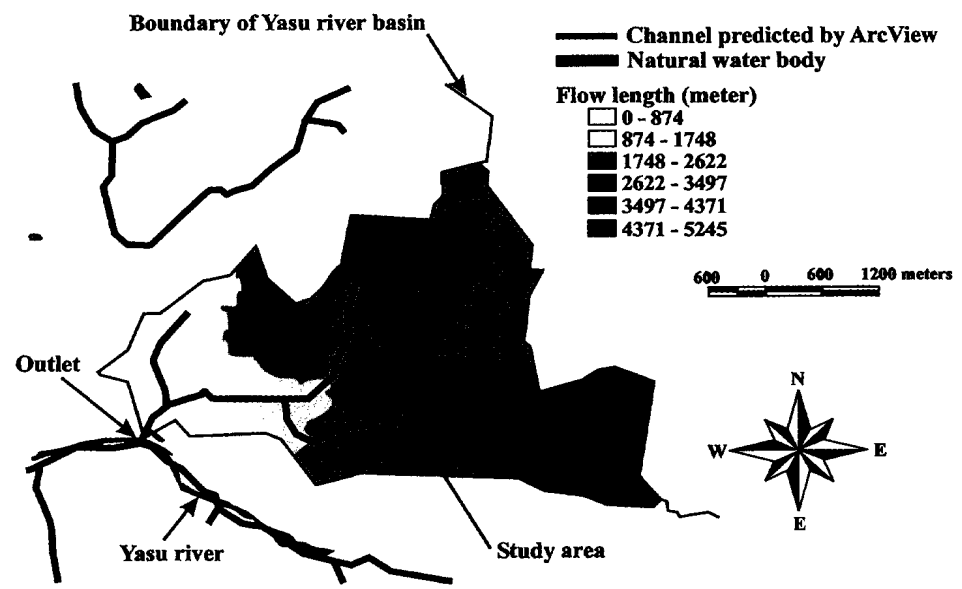

Figure 3: Flow length for study area

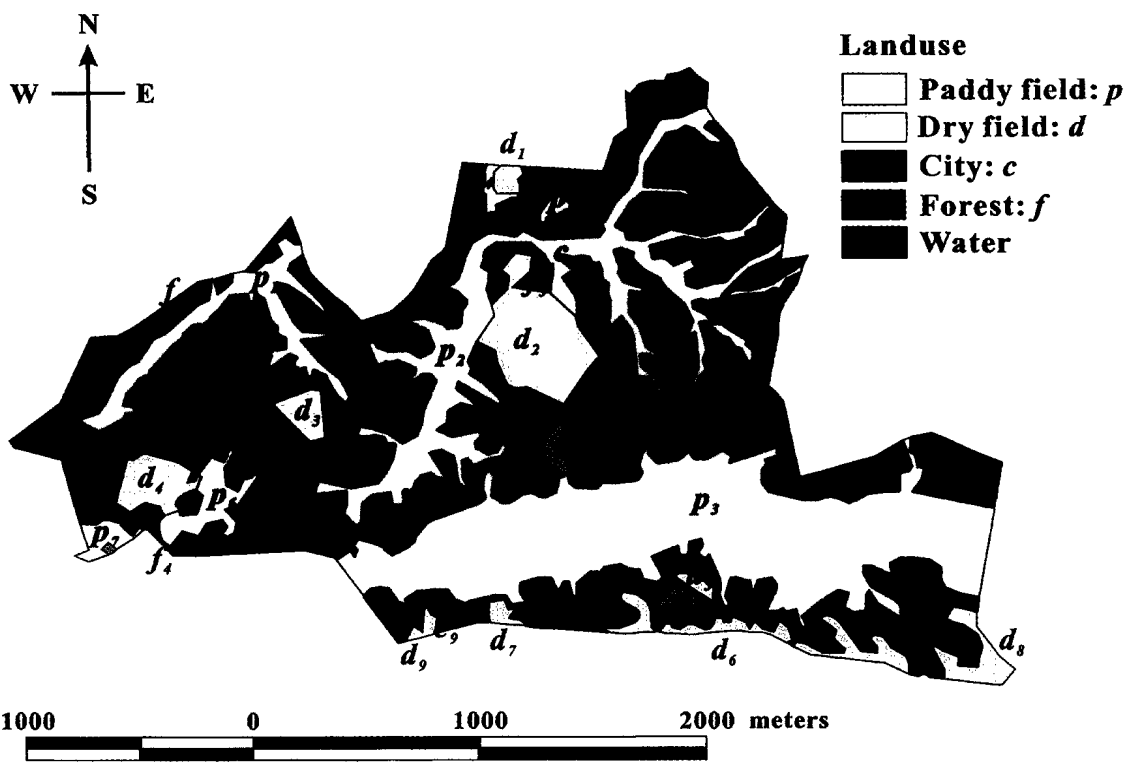

Figure 4: Landuse and defined LMUs for study area 


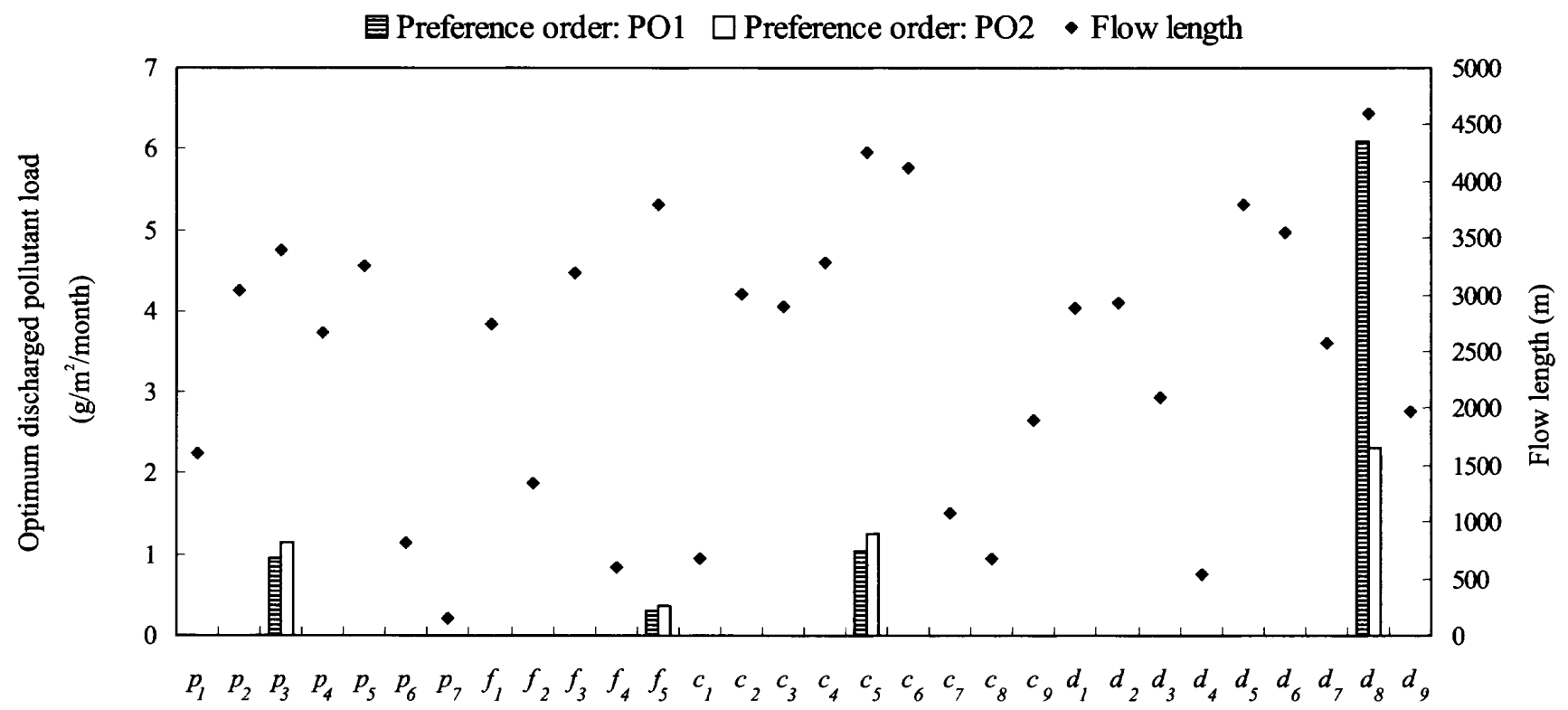

LMU

Figure 5: Optimum allocated pollutant loads for different preference orders PO1 and PO2

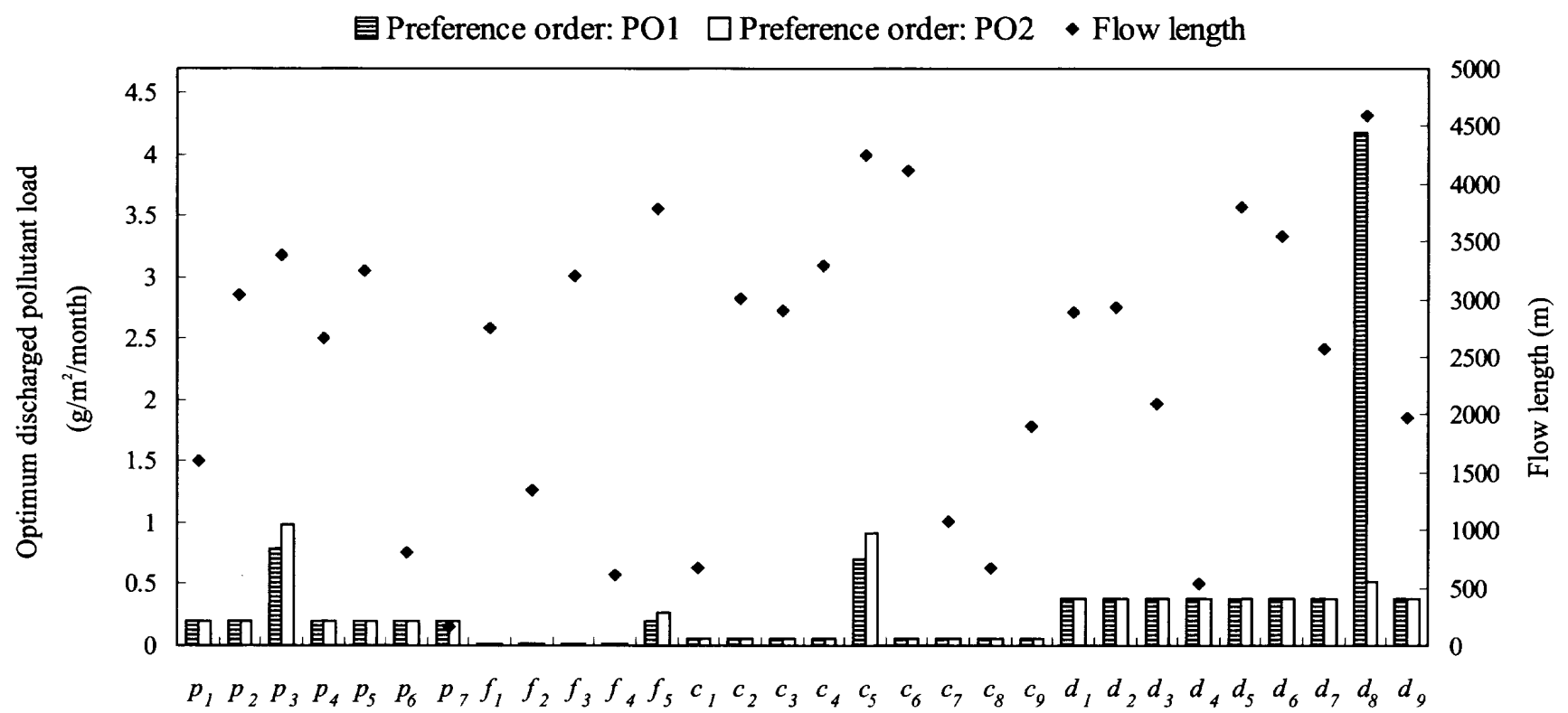

LMU

Figure 6: Optimum allocated pollutant loads for different preference orders $\mathrm{PO} 1$ and $\mathrm{PO} 2$ with defined lower limits 


\subsection{Optimization}

In the present study, only T-N (Total Nitrogen) is considered as a pollutant type. The value of $\lambda$ for T-N is assumed $0.0001 \mathrm{~m}^{-1}$ on the basis of study of Ha et al. (1998). The effluent standard value of pollutant at the outlet of watershed $(\bar{L})$ can be decided by a management model of river water quality. However, it is not available at moment, so it is calculated using values of the unit loading factor (Soumiya, 2000) and total area attributed to different polygons. The values of unit loading factor used for estimating the value of $\bar{L}$ in this study are $0.38 \mathrm{~g} / \mathrm{m}^{2} / \mathrm{month}$ (paddy fields), $0.77 \mathrm{~g} / \mathrm{m}^{2} /$ month (dry fields), $0.034 \mathrm{~g} / \mathrm{m}^{2} /$ month (forests) and $0.11 \mathrm{~g} / \mathrm{m}^{2} /$ month (cities). The calculated value of $\bar{L}$ used here is $1,294,406.46 \mathrm{~g} /$ month. Initially, the values of $\alpha, \beta$, and $\gamma$ are considered as $0.494,11.177$ and 3.454 , respectively. In this case, preference order is assumed PO1 "1) Dry field 2) Paddy field 3) City 4) Forest". The lower limit of allocated pollutant in (6)-(9) is set to $0 \mathrm{~g} / \mathrm{m}^{2} /$ month in each LMU.

The above optimization problem is solved by the simplex method. The optimum solution obtained is shown in Figure 5. It is observed that LMUs having higher flow length in each type $\left(p_{3}, f_{5}, c_{5}\right.$, and $\left.d_{8}\right)$ get higher value of discharged pollutant load allocated, whereas other LMUs, which have lower flow length, get lower limit of discharged pollutant load allocated. Optimum solutions for $p_{3}, f_{5}, c_{5}$, and $d_{8}$ are 0.95085 , $0.29784,1.03382$ and $6.08323 \mathrm{~g} / \mathrm{m}^{2} / \mathrm{month}$, respectively. All other LMUs have the optimum value of $0 \mathrm{~g} / \mathrm{m}^{2} /$ month. The total pollutant load from all the LMUs is $1,889,475 \mathrm{~g} /$ month. However, when the preference order is changed from PO1 to PO2 "1) Paddy field 2) Dry field 3) City 4) Forest", by changing the value of $\alpha$ to 1.583 , the optimum values change. In the latter case, the optimum discharged pollutant load shifts towards paddy field LMU (Figure 5), and then LMUs $p_{3}, f_{5}, c_{5}$, and $d_{8}$ get the optimum discharged pollutant load values of 1.1539 , $0.36145,1.25458$ and $2.30097 \mathrm{~g} / \mathrm{m}^{2} / \mathrm{month}$, respectively. Also in this case, all other LMUs have optimum value of $0 \mathrm{~g} / \mathrm{m}^{2} /$ month. In Figure 5 , it can be observed that despite the preference order PO2 (paddy field LMUs getting higher weightage than dry field LMUs), the optimum discharged pollutant load value for $p_{3}$ is less than that of $d_{8}$. This can be attributed to the fact that total area of paddy fields $\left(p_{3}\right)$ is larger than that of dry fields $\left(d_{8}\right)$. Also, it is observed that optimized values of allocated pollutant load are sensitive to the preference order of LMU. The total pollutant load from all LMUs in this case is $1,855,042 \mathrm{~g} /$ month.

Optimization is also carried out by defining a minimum lower limit value in (6)-(9). This is due to the consideration that practically it is not possible to have LMU discharging zero pollutant load. The values of lower limit, $L_{p_{i}}^{l}, L_{d_{i}}^{l}, L_{f_{i}}^{l}$, and
$L_{c_{i}}^{l}$, are given on the basis of values of unit loading factors, as discussed above, and are taken as $0.19 \mathrm{~g} / \mathrm{m}^{2} /$ month (paddy fields) $0.385 \mathrm{~g} / \mathrm{m}^{2} / \mathrm{month}$ (dry fields), $0.017 \mathrm{~g} / \mathrm{m}^{2} /$ month (forests) and 0.055 $\mathrm{g} / \mathrm{m}^{2} /$ month (cities), respectively. Thus, the constraints in (6)-(9) in this case become:

$$
\begin{array}{lll}
L_{p_{i}} \geq 0.19 & i=1,2, \ldots, I_{p} \\
L_{d_{i}} \geq 0.385 & i=1,2, \ldots, I_{d} \\
L_{f_{i}} \geq 0.017 & i=1,2, \ldots, I_{f} \\
L_{c_{i}} \geq 0.055 & i=1,2, \ldots, I_{c}
\end{array}
$$

The linear programming problem is solved again using the lower limit constraints (10)-(13). The optimum solutions for this case, for both of the preference orders PO1 and PO2, are shown in Figure 6 . Preference orders PO1 and PO2 in this case also are the same as defined above. For both preference orders PO1 and PO2, all the LMUs (except LMUs $p_{3}$, $f_{5}, c_{5}$, and $d_{8}$ ) get the same optimum discharged pollutant load as its defined lower limit value (Figure 6). In this case, for PO1, optimum solutions for $p_{3}, f_{5}$, $c_{5}$, and $d_{8}$ are $0.78412,0.2031,0.70095$ and 4.18596 $\mathrm{g} / \mathrm{m}^{2} /$ month, respectively, and for PO2 the corresponding optimum solutions are 0.98054, 0.26463, 0.63304 and $0.52716 \mathrm{~g} / \mathrm{m}^{2} /$ month, respectively. Total pollutant load from all LMUs for PO1 is $1,827,795$ $\mathrm{g} /$ month and that for PO2 is $1,794,486 \mathrm{~g} /$ month.

\section{Conclusion}

The optimization model for allocating pollutant from non-point sources is developed. ArcView GIS is used to model the study area and to compute the flow length and area of the LMU. The method is demonstrated in a sub-watershed of the Yasu river basin. The values of optimum discharged pollutant load from different LMUs are observed to be sensitive to preference order of type of LMUs. The model can be used for allocating optimum discharged pollutant loads from LMUs in a drainage basin based on preference order of decision maker's choice. Further studies will be required to estimate a more appropriate value of self-purification coefficient, $\lambda$, to generate more reliable solutions.

\section{Acknowledgements}

The authors would like to extend their gratitude to the Department of Lake Biwa and the Environment, Shiga Prefectural Government, Japan, for providing GIS source data for Yasu river basin.

\section{References}

[1] Basnyat, P., Teeter, L.D., Lockaby, B.G. and Flynn, K.M. (2000): The use of remote sensing and GIS in watershed level analyses of non-point source pollution problems, Forest Ecology and Management, 
128, pp.65-73.

[2] ESRI (1996): ArcView Spatial Analyst - Advanced Spatial Analysis Using Raster and Vector Data, Environmental Systems Research Institute Inc., CA, USA.

[3] Ha, S.R., Jung, D.I. and Yoon, C.H. (1998): A renovated model for spatial analysis of pollutant runoff loads in agricultural watershed, Water Science and Technology, 38(10), pp.207-214.

[4] Leon, L.F., Soulis, E.D., Kouwen, N. and Farquhar, G.J. (2000): Nonpoint source pollution: A distributed water quality modeling approach, Water Research, 35(4), pp.997-1007.

[5] Pegram, G.C. and Bath, A.J. (1995): Role of nonpoint sources in the development of a water quality management plan for the Mgeni river catchment, Water Science and Technology, 32(5-6), pp.175-182.
[6] Randhir, T.O., Lee, J.G. and Engel, B. (2000): Multiple criteria dynamic spatial optimization to manage water quality on a watershed scale, Transactions of the ASAE, 43(2), pp.291-299.

[7] Rejesus, R.M. and Hornbaker, R.H. (1999): Economic and environmental evaluation of alternative pollution-reducing nitrogen management practices in central Illinois, Agriculture Ecosystems and Environment, 75 , pp.41-53.

[8] Soumiya, I. (2000): Lake Biwa - The Environment and Water Quality, Gihodo Publications, pp.155 (in Japanese).

[9] Young, R.A., Onstad, C.A., Bosch, D.D. and Anderson, W.P. (1989): AGNPS: A nonpoint source pollution model for evaluating agricultural watersheds, Journal of Soil and Water Conservation, 44(2), pp.168-173.

[Discussion open until June 30, 2002] 